\title{
Assuring Quality in Online Offerings: Insights from A University's Faculty
}

\author{
Connie B. Budden, Southeastern Louisiana University, USA \\ Heather L. Budden, Louisiana Tech University, USA \\ Michelle Hall, Southeastern Louisiana University, USA \\ Debbie G. Longman, Southeastern Louisiana University, USA
}

\begin{abstract}
As the growth of online education offered by universities accelerates and spreads, universities are increasingly grappling with concerns related to widespread availability and the maintenance of academic quality. The "Quality Matters at Southeastern" Program fosters quality through a peer review process and offers a certification process to help assure quality in the University's online and blended course offerings. This report is a look at perceived impacts of the internal certification process by faculty.
\end{abstract}

Keywords: Quality Matters at Southeastern Program; Online Education; Certification

\section{INTRODUCTION}

ccording to the SREB (2006) the rapid growth of online learning in the previous 10 years witnessed an increasing concern on the concept of what constitutes a quality online course. Major improvements have taken place in technology and the ability of faculty to impact increasing numbers of students who seek out online education. Also, an improved understanding of technology savvy students allows educators to better serve the needs of those students.

Online learning began in the 1990s and the increased access to innovative technology and the use of new pedagogy have broadened individuals' access to higher education. Many colleges and universities were concerned and remain concerned about the issue of assuring the delivery of quality online educational programs. This concern is central to discussions of online-delivery, as educators have long recognized that assessing good teaching in a classroom environment is not an easy task. Compared to face-to-face delivery assessments, assessing online offerings presents new and potentially increased difficulties to any assessment process and complicates efforts to assure quality. Quality issues are often included in discussions on teaching effectiveness, faculty-to-student ratios, attrition rates, and student satisfaction (Chao, Saj, Tessier 2006).

Southeastern Louisiana University instituted an internal, faculty-centered program that allows for faculty members who wish to teach either $100 \%$ online or blended online (partial online/partial in-class) courses to provide documentation their efforts exude quality. The program provides a peer-reviewed level of quality in the University's online and blended courses. Faculty reviewers use a blind-review process to assess course designs and materials to assure they meet the university's standard of excellence in all online offerings. The university's program is not related to any external or national program. It is totally in-house.

To prepare faculty to participate and benefit from the program, the university offers and encourages faculty to complete an online course concerning program expectations and the review process which is conveniently accessed through its Moodle website. At the end of spring 2014, 96 of the 499 full-time faculty members had achieved Quality Matters at Southeastern certification. Indeed, all faculty now teaching online courses have achieved the university's faculty certification expectation. 


\section{THE UNIVERSITY'S WEBSITE COURSE OVERVIEW}

The university's Moodle site has a section available to faculty wishing to pursue quality certification. The website was designed to provide faculty members with current information and exercises designed to acquaint users with the "Quality Matters at Southeastern" program. The site mentions that Quality Matters at Southeastern is a collegial review process where fellow faculty members provide feedback on course design and delivery in two ways: (1) the awarding of points for meeting specific review standards, and (2) providing substantial, constructive, and specific comments and suggestions with regard to both areas for improvement while recognizing existing strengths (Budden and Budden, 2013).

Reviewers are asked to take the student's perspective with regard to clarity and organization in addressing their assessments of learning relative to the quality expectations of the university's program. The assessment rubric and review processes are dynamic and reflect agreed-upon standards of best practice as found in the literature.

Learning Objectives for pursuing Quality Matters at Southeastern certification are presented. To gain university certification, faculty members are expected to be able to:

- Describe the critical materials, processes, and administrative elements of the online course quality assurance program.

- $\quad$ Apply the Peer Course Review rubric and scoring system to online or hybrid courses.

- Write useful recommendations/critiques for course development, modification and/or enhancement.

The material is presented in four basic learning units. Unit 1 describes the program's philosophy. Learning unit 2 discusses designing a quality online experience for students. Learning unit 3 presents the quality rubric and standards and the meeting the necessary to get certified. The fourth unit discusses the concept of a team and review process, including a quiz. At the completion of the four primary units a final evaluation and quiz is presented to check understanding of the process. All activities must be completed and an overall score of 85 is necessary to successfully complete the course (Budden and Budden, 2013) and gain "Quality Matters at Southeastern" certification. In the university's program, faculty need first to be certified through the university's program before being able to submit specific courses to be considered for individual class certification. Thus, it is possible for an individual to be certified, and yet not have courses certified. At the same time, it is not possible to have courses certified without prior faculty certification.

\section{THE PRELIMINARY INVESTIGATION}

This study is a follow-up to a preliminary study conducted in 2012 (see Budden and Budden, 2013) of a small group of certified business school faculty. In that preliminary look, faculty participants mentioned benefits of the process: they added clarifying information to their online offerings, they felt their course structures had been improved, they felt the course interface had become more stable and consistent and that important information had become more visible in the course. They also mentioned that the effort had made them concentrate more on the material to be covered due to the structure of the process.

At the same time, some felt the process had not improved their instruction. Among the concerns mentioned by the respondents: training was time consuming, instructions were not as clear as they would have liked, the process was not encouraged by administration, and the process removed some creativity from the teaching process. Indeed, the need to encourage certification through some reward program was proffered by more than one. So while benefits were mentioned, some challenges were also addressed.

That investigation was a preliminary look at the Quality Matters at Southeastern Process certification process; it was a small study. This study improves on the previous study in that all certified faculty on campus were included in the population. Of 96 certified faculty, 94 responded to this study. Again, Southeastern's program is a unique entity, and unrelated to any external, quality program. 
The first concern of the researchers was the perceived amount of time it takes for the typical faculty member to achieve certification through the process. According to those who responded, the time spent in the Quality Matters at Southeastern Program certification process took some less than four hours while others needed somewhat more than 16 hours. The good news for those considering pursuing program certification, a full two-thirds $(67.9 \%)$ indicated the process took them less than eight hours.

Faculty Time Spent in the Online Certification Process

\begin{tabular}{lc}
\hline \multicolumn{1}{c}{ Online Hours to Complete the Process } & Percentage of Respondents \\
\hline Less than 4 hours & $27.4 \%$ \\
More than 4 hours, less than 8 hours & $40.5 \%$ \\
8 or more hours, less than 16 hours & $22.6 \%$ \\
At least 16 hours & $9.5 \%$ \\
\hline
\end{tabular}

Many proponents of the process expect the process will improve the organization of online or hybrid classes. Of those responding to the survey, slightly over one-half $(51.8 \%)$ indicated it had improved their course organization. Approximately, the same percentage felt the process had been beneficial to the learning environment. One-fourth felt it had not improved their organizational efforts nor had been beneficial to their classes.

Surprisingly, only $27 \%$ of respondents perceived an increase in student satisfaction with the course after the faculty member's certification. At the same time, $39 \%$ had no indication one way or the other as to the impact on their students' satisfaction levels. Interestingly, approximately $50 \%$ of certified respondents felt the process had improved the effectiveness of their delivery.

Perceptions of Student Satisfaction and Course Effectiveness

\begin{tabular}{lccc}
\hline & Disagree & Neither & Agree \\
\hline Increased Student Satisfaction & $34 \%$ & $39 \%$ & $27 \%$ \\
Improved Course Effectiveness & $31 \%$ & $20 \%$ & $49 \%$ \\
Improved Course Structure & $29 \%$ & $25 \%$ & $46 \%$ \\
Increased Material Covered & $47 \%$ & $28 \%$ & $25 \%$ \\
\hline
\end{tabular}

*rows may not equal $100 \%$ due to rounding

Just short of one-half (46\%) of respondents felt the process had resulted in their improving the structure of their courses. At the same time, $47 \%$ felt the process had not allowed them to increase the amount of materials they normally would have covered during the semester.

Some would argue if the purpose of the process is to improve online delivery, and if the University is serious about improving online delivery, then certification should be required to teach online courses and should therefore be rewarded. Respondents viewed these issues from different perspectives.

Mandated Role and Encouragement

\begin{tabular}{lccc}
\hline & Disagree & Neither & Agree \\
\hline Should be required for hybrid or 100\% online courses & $25 \%$ & $15 \%$ & $60 \%$ \\
My College Encourages Certification & $15 \%$ & $15 \%$ & $69 \%$ \\
My Department Encourages Certification & $17 \%$ & $10 \%$ & $74 \%$ \\
\hline
\end{tabular}

*rows may not equal $100 \%$ due to rounding

Of the respondents, $60 \%$ felt that University certification should be required in order to teach hybrid (blended) courses in which at least $50 \%$ of the component is online. Only one-fourth of respondents felt that certification should not be required to teach courses with an online component. At least $70 \%$ of respondents indicated both their departments and their colleges encouraged University certification. 


\begin{tabular}{lccc}
\multicolumn{3}{c}{ Perceived Role of Potential Rewards in the Process } & \\
\hline & Disagree & Neither & Agree \\
\hline Rewarded with a stipend & $18 \%$ & $13 \%$ & $69 \%$ \\
Rewarded with preference for summer teaching & $23 \%$ & $18 \%$ & $59 \%$ \\
Rewarded with one-time teaching load reduction & $33 \%$ & $14 \%$ & $53 \%$ \\
Rewarded with a graduate assistant & $33 \%$ & $20 \%$ & $47 \%$ \\
\hline
\end{tabular}

*rows may not equal $100 \%$ due to rounding

The majority of respondents felt faculty who go through the process should be rewarded in some manner. Stipends were the preferred manner of reward mentioned (69\%). A significant percentage (59\%) believed certified faculty should receive preferential summer teaching assignments. Slightly more than one-half (54\%) believed a one-time reduction in teaching load would be a suitable reward, while $47 \%$ felt a graduate assistant assigned to the faculty member would be a suitable reward. As one might have hypothesized prior to the study, stipends and summer teaching (which results in extra compensation) were the top two reward choices of the respondents.

Online class presence in the learning environment is no longer a question. Such classes are part of the norm and will only make further inroads into academe. Universities should strive to provide convenient and helpful programs to ensure quality and consistency among online offerings. The important role that quality and consistency plays in the learning environment cannot be over emphasized. A certification process and adherence to high standards should be encouraged and rewarded.

This was a study of the perceptions of the faculty members who have achieved "Quality Matters at Southeastern" program certification. The preliminary study conducted in 2013 was used to develop the questionnaire that assessed campus-wide knowledge and satisfaction with the certification process. The finding that $49 \%$ of respondents felt the process had improved their effectiveness is significant, as the on-campus effort has not been in existence long. Further, study of the impact on students should be conducted.

\section{AUTHOR INFORMATION}

Connie B. Budden is an instructor of Management at Southeastern Louisiana University, USA. Her research interests include business education, global business, human resource management issues and business sustainability. E-mail: cbudden@selu.edu (Corresponding author)

Heather L. Budden is a doctoral student in management at Louisiana Tech University. Her research interests include organizational behavior, human resource development and global management.

Michelle Hall, Ph. D., is director of the University's Institutional Research Office. Her research interests include assurance of learning, student outcomes and learning enrichment.

Debbie G. Longman, Ph.D,_is Professor of General Studies and Director of the "Quality Matters at Southeastern" program. She holds faculty certification by the Quality Matters program. Her research interests include assurance of learning, quality improvement and student outcomes.

\section{REFERENCES}

Budden, C.B. and Budden, M.C. (2013). A look at an implementation of the quality matters program in a collegiate environment: Benefits and challenges. Contemporary Issues In Education Research, 6(4), 381-384.

Chao, T., Saj, T., \& Tessier, F. (2006). Establishing a quality review for online courses, Educase Quarterly, 3, 3239. Retrieved from https://net.educase.edu. Retrieved from www.qualitymatters.org

Southern Regional Education Board, Standards for quality online course. Retrieved from www.sreb.edu. 